\title{
Instrução e assistência na capitania de Minas Gerais: das ações das câmaras às escolas para meninos pobres (1750-1814)*
}

\author{
Thais Nivia de Lima e Fonseca \\ Universidade Federal de Minas Gerais, Faculdade de Educação
}

No mundo luso-brasileiro do século XVIII e primeiras décadas do XIX, a instrução e a assistência estiveram muito próximas, envolvendo o Estado e a Igreja e movidas tanto pela necessidade do controle social por meio da educação para o trabalho como de civilizar os povos por meio da difusão dos valores morais e religiosos, principalmente para as camadas mais baixas da população. Essa educação ocorreria predominantemente em instituições assistencialistas de ordens religiosas ou patrocinadas por recursos privados. O objetivo do ensino das primeiras letras seria, fundamentalmente, facilitar o aprendizado da doutrina, sem implicar a criação de possibilidades de ascensão social pela educação. A educação profissional era, então, prioritária para o aprendizado de ofícios mecânicos que pudessem servir de ocupação e de sustento.

* Artigo decorrente de pesquisa financiada pela Fundação de Amparo à Pesquisa do Estado de Minas Gerais (FAPEMIG) e pelo Conselho Nacional de Desenvolvimento Científico e Tecnológico (CNPq), com bolsa de estágio pós-doutoral concedida pela Coordenação de aperfeiçoamento de Pessoal de Nível Superior (CAPES).
A legislação, válida em todo o Império português, demonstrava clara preocupação com os meios de reunir instrução e assistência, indicando procedimentos legais diferenciados para cada segmento social. As Ordenações do Reino são pródigas na matéria e determinavam que a criação e a manutenção de órfãos que tivessem bens estariam garantidas por sua própria herança (Almeida, 1870; Adão, 1997). Os órfãos sem posses e nascidos em condições especiais - como os filhos de religiosos, os filhos ilegítimos de indivíduos casados ou solteiros - seriam criados nas instituições de assistência, como os hospitais e albergarias, quando houvesse, ou então pelas rendas das câmaras. Segundo a lei, a educação desses indivíduos deveria ser compatível com sua origem, isto é, os filhos de lavradores deveriam ser criados por famílias de lavradores e seriam usados no serviço do campo, aprendendo a ocupação de seus pais. O mesmo ocorreria aos filhos de oficiais mecânicos; nesse caso, haveria a possibilidade do uso dos bens do órfão para pagamento dos mestres de ofício, o que indica maiores disponibilidades materiais nesse segmento. A distinção entre as estratégias para diferentes 
grupos sociais ficava ainda mais clara na medida em que a lei definia que os órfãos que não fossem filhos de trabalhadores manuais e que não precisassem ser dados à criação paga pelo Estado seriam educados à custa de sua própria herança, administrada por um tutor ou curador (Almeida, 1870, p. 212).

Recaía sobre os tutores a responsabilidade pelo encaminhamento da educação dos órfãos, fosse ela a instrução elementar ou a formação profissional. Mas, no Brasil, nem sempre esta última apresentavase atrelada à tradição familiar ou à condição social, como indicavam as ordenações, particularmente na capitania de Minas Gerais, onde foi notável o envolvimento de filhos mestiços de homens abastados no aprendizado de ofícios mecânicos, às vezes combinado ao aprendizado das primeiras letras. Era uma situação muitas vezes decorrente da instável posição ocupada por esses indivíduos, nem sempre filhos legítimos, que não tinham garantido o benefício da herança e se encontravam na encruzilhada entre dois mundos. O aprendizado dos ofícios mecânicos aparecia, então, como possibilidade concreta de ocupação e de sustento material. Essa combinação aparecia também na vida de indivíduos de origens mais modestas, como filhos de oficiais mecânicos, mas que chegaram a freqüentar uma escola de ler, escrever e contar. Isso significaria uma ligeira ampliação da possibilidade de ascensão na sociedade colonial, por meio das habilidades de leitura e de escrita, mesmo que limitadas (Fonseca, 2006).

Muitos desses indivíduos tiveram acesso a essa educação combinada por meio da atuação de seus parentes ou de seus tutores; outros, já no século XIX, por meio do ingresso em instituições de acolhimento de crianças e jovens pobres, nem sempre na condição de órfãos. Um exemplo dessas estratégias é o caso de Antonio, filho natural de Antonia Rangel, parda forra, solteira, falecida em 1757 na localidade de Igreja Grande, Vila de Sabará. O tutor de Antonio, capitão José Ribeiro de Carvalho, prestando contas ao juiz de Órfãos onze anos depois, afirmava que tinha em seu poder o órfão antes mesmo da morte da mãe, por ele ser seu filho, sempre
[...] sustentando e vestindo-o de todo o necessário e mandou ensinar a ler e escrever, em que fez despesa, e depois lhe mandou ensinar o oficio de alfaiate, de que pouco usou. Presentemente se acha exercitando de escrever papéis no cartório da Ouvidoria, de cujos lucros se veste e trata. Porém o suplicante [tutor] o tem em sua casa e o sustenta. (MO/ ACBG/IPHAN, 1757)

Se em muitas capitanias da América portuguesa foram abertos estabelecimentos que podiam abrigar órfãos e expostos pobres, dar-lhes sustento e educação, nas Minas Gerais sua existência foi tardia e menos vinculada à Igreja, pois nessa capitania a presença das ordens religiosas foi proibida no início do século XVIII, e a assistência associada à instrução limitou-se à sua dimensão leiga. ${ }^{1}$ Por isso, as irmandades leigas e ordens terceiras assumiram a tarefa, construindo igrejas e cemitérios, organizando as festas, cuidando dos necessitados, estimulando as artes e os ofícios. As irmandades representavam garantia de inserção social e de proteção, principalmente para os segmentos menos favorecidos. Pertencer, pois, a uma irmandade significava dar legitimidade às práticas religiosas, possibilitar o auxílio para as eventuais dificuldades da vida (como empréstimos de dinheiro, ajuda em casos de doença, viuvez ou orfandade), garantir o sepultamento e a celebração de missas pelas almas.

Essas associações patrocinavam a construção das igrejas e sua decoração em pintura e escultura e encomendavam a composição de músicas para os ofícios religiosos, o que garantia o mercado de trabalho para um grande número de artistas e artesãos nos núcleos urbanos da capitania de Minas Gerais. Sua atuação na educação é ainda pouco conhecida, pois os estudos têm dado maior atenção ao seu papel no jogo das relações de poder envolvendo o Estado e a Igreja e à sua atuação no desenvolvimento da arte barroca, especialmente em Minas Gerais (Boschi, 1986; Campos, 1994, 1998). Suas ações conhecidas

${ }^{1}$ Pela Carta Régia de 9 de junho de 1711, foi proibida a entrada nas Minas do clero regular e de padres seculares sem paróquias, além de ser ordenada a sua expulsão do território. 
até o momento referem-se mais à assistência do que à educação. No século XVIII foram estabelecidos os hospícios da Terra Santa em Vila Rica e em Sabará, com a colaboração dos Terceiros de São Francisco de Assis, e a Casa de Misericórdia foi instalada com seu hospital em Vila Rica em 1738, gerida pelo compromisso de sua congênere do Rio de Janeiro (REVISTA DO ARQUIVO PÚBLICO MINEIRO, 1911, p. 399). ${ }^{1} \mathrm{~A}$ Ordem Terceira de Nossa Senhora do Monte do Carmo de Sabará recebeu, em 1787, a incumbência de gerir um hospital mantido por bens vinculados, que depois passou à Misericórdia da mesma vila (Passos, 1929; Barbosa, 1985; Matos, 1981; Vasconcelos, 1995).

$\mathrm{O}$ atendimento a outras necessidades sociais e religiosas nas Minas fez-se também por meio de dois recolhimentos femininos, a Casa de Oração do Vale das Lágrimas, na Comarca do Serro Frio, e o Recolhimento de Nossa Senhora da Conceição das Macaúbas, situado na Comarca do Rio das Velhas. Essas instituições não visavam primordialmente nem à instrução nem ao desenvolvimento de vocações religiosas das recolhidas, mas acabaram sendo reconhecidas por sua importância para a educação das mulheres. Para lá eram enviadas tanto filhas de famílias abastadas quanto meninas sem posses, geralmente órfãs, brancas ou não, com o intuito de separálas das coisas mundanas e, sendo possível, encaminhálas para o casamento (Carrato, 1968; Algranti, 1993). ${ }^{2}$ A importância que esses recolhimentos adquiriram era atestada pelas autoridades locais e pela população eles eram reconhecidos como úteis para a "educação da mocidade", pois as moças ali recolhidas davam "exemplos de virtude dignos de se imitarem", conforme as informações dadas pelo governador da capitania, Luis da Cunha Meneses, sobre a Casa de Oração do Vale das Lágrimas (REVISTA DO ARQUIVO PÚBLICO MINEIRO, 1911). Atestando sua importância para a educação apropriada às mulheres, o comandante do Destacamento de Minas Novas informava sobre a utilidade do recolhimento,

${ }^{2}$ Um dos casos mais conhecidos é o das nove filhas da mulata Chica da Silva e do contratador João Fernandes de Oliveira, recolhidas em Macaúbas e lá sustentadas por somas consideráveis enviadas por seu pai (Furtado, 2003). para o qual alguns pais de família mandavam "ensinar suas filhas, tendo-as recolhidas por alguns anos, e dali costumam sair não só provectas em artes liberais, mas também no Santo Amor, e temor de Deus" (REVISTA DO ARQUIVO PÚBLICO MINEIRO, 1911).

A atuação educacional mais direta da Igreja ocorreu com a criação do Seminário de Mariana, em 1750, sob a jurisdição do bispado da mesma cidade. O seminário recebia os que tencionavam a vida eclesiástica, mas também os que almejavam preparar-se para o ingresso na Universidade de Coimbra, o que o afasta do assistencialismo. Foram muitos os filhos das elites que nele ingressaram, indo depois para Portugal para completar os estudos, trajetória que era evidentemente uma forma de assegurar o ingresso nos quadros da administração colonial no exercício de postos prestigiados e que facilitavam a obtenção de privilégios (Valadares, 2004; Carrato, 1968).

Embora devessem aprender os ofícios mecânicos, os pobres podiam eventualmente aprender a ler, escrever e contar. Nos inventários, nas indicações destinadas aos tutores e curadores de órfãos, percebem-se as estratégias e as práticas educativas referentes aos aprendizes. Nesses documentos especificavam-se os gastos dos tutores com cada órfão, entre os quais os pagamentos dos mestres e mestras de ofício e dos professores de primeiras letras. Além de declarar o estado de saúde dos órfãos, seus domicílios e o cumprimento das obrigações a eles incumbidas, os tutores registravam a compra de itens como vestuário, remédios, alimentação e material escolar e de traba1ho. A análise desses documentos aclara as diferentes ações quanto à educação para homens e mulheres, a educação profissional para os órfãos pobres ou de menores posses, a instrução elementar por meio do aprendizado das primeiras letras, além de indicações quanto às idades adequadas para o envio de crianças à escola ou os impedimentos definitivos para isso, como deficiências físicas e intelectuais, segundo o julgamento da época.

Os casos de reconhecimento de paternidade nos testamentos e inventários revelam muitas vezes alterações das estratégias educativas destinadas aos 
órfãos, quando os pais expressavam seu desejo de vê-los na escola de primeiras letras, sem descartar a via da educação profissional.

A preocupação das autoridades quanto às condições materiais da população manifestou-se desde os primeiros tempos de ocupação da zona de mineração do ouro e foi acrescida das questões relativas à formação étnica e à qualidade e condição da população, formada, desde os primeiros decênios, de considerável contingente de negros e de mestiços, livres e escravos. A falta de mulheres brancas agravava o quadro, e proliferavam, mais do que desejariam as autoridades, os nascimentos ilegítimos, a exposição de crianças e o número de órfãos pobres. Como acontecia no Reino, também na América essa era questão de relevo, e urgia fazer com que se cumprisse a legislação em relação aos órfãos e expostos, procurando garantir sua educação e instrução, além dos assuntos referentes às heranças e direitos sobre bens e pessoas.

A descrença das autoridades quanto às possibilidades de promoção da educação da população das Minas perpassou todo o século XVIII e fundava-se não apenas na desconfiança em relação à sua composição étnica como também à sua origem social, incluindo os portugueses pobres emigrados. Segundo o desembargador José João Teixeira Coelho, eles viviam em Minas Gerais em excessivas liberdades, insolentes e querendo ser fidalgos. Perguntava o desembargador: "Que educação podem dar a seus filhos uns homens daquela qualidade? E que virtudes têm eles que sirvam de exemplo aos mesmos filhos?" (Coelho, 1994, p. 254-255).

Portanto, cuidar da educação de órfãos, sobretudo os pobres, era medida preventiva de interesse do Estado, não tendo havido, no entanto, efetivos esforços para sua concretização. Muitas vezes, a educação desses segmentos da sociedade mineira setecentista dependia das iniciativas da própria população, seja nos limites das ações das associações religiosas leigas ou das iniciativas das próprias famílias, que, quando podiam, buscavam meios de oferecer educação para seus filhos. Por isso, foi aí relevante a atuação de professores particulares, principalmente de primeiras letras, mesmo depois da instituição das aulas régias, bem como dos mestres de ofícios mecânicos.

A análise da dimensão assistencial na Capitania de Minas Gerais, particularmente na Comarca do Rio das Velhas - cuja sede era a Vila de Nossa Senhora da Conceição do Sabará ${ }^{3}$ - indica uma presença significativa de órfãos pobres e de expostos sendo criados pelas rendas da Câmara, de acordo com a legislação. ${ }^{4}$ Não houve, nessa região, a instalação de rodas de expostos; a única Santa Casa de Misericórdia foi criada somente em 1832, e por isso as crianças eram geralmente deixadas às portas das casas dos moradores ou da Câmara da Vila. Sua criação e educação acabavam a cargo de homens e mulheres que recebiam auxílio público para isso. A Câmara de Sabará pagava a quantia de 12 oitavas anuais de ouro e, embora não fosse quantia avultada, os pagamentos atrasavam sempre, por vários anos. No século XVIII, no Brasil, uma oitava de ouro valia, em média, 1.400 réis e seria a quantia mensal paga pela criação de um exposto, sem incluir valores adicionais para o pagamento de mestres de oficio ou de primeiras letras. Os valores cobrados pelos professores particulares de primeiras letras, por exemplo, eram muito variáveis, podendo oscilar de 130 a 700 réis mensais, por aluno. ${ }^{5}$

Uma parte nada desprezível dos criadores era formada de pessoas pobres, para quem esses valores, embora baixos, eram significativos. Nos requerimentos e petições enviados por eles à Câmara solicitando o

${ }^{3}$ A Comarca do Rio das Velhas foi, nos séculos XVIII e XIX, a maior em extensão, ligando-se às capitanias da Bahia, do Rio de Janeiro, de São Paulo, do Espírito Santo, de Pernambuco e de Goiás, e sua sede, a Vila de Nossa Senhora da Conceição do Sabará, um dos maiores e mais dinâmicos núcleos urbanos da capitania de Minas Gerais.

${ }^{4}$ Não havendo instituições para o acolhimento dos órfãos e expostos pobres, as Câmaras providenciariam sua criação, até os sete anos de idade, por meio do pagamento aos criadores.

${ }^{5}$ A título de comparação, o ordenado de um professor régio variava de 80 mil a 460 mil réis anuais, dependendo do seu nível (se substituto ou titular) e da sua cadeira (primeiras letras ou latim, por exemplo). 
pagamento em atraso, há indícios importantes sobre as relações construídas entre os indivíduos envolvidos na criação dessas crianças e as estratégias construídas para promover sua educação, bem como dados sobre suas idades, condição social e etnia.

Diz Joanna de Souza Teles, moradora da Lagoa Santa, que sendo exposto em casa de Maria Roza de Macedo um menino por nome Manoel, a suplicante o tem criado, e educado e presentemente o tem nas escolas de primeiras letras e Musica como tudo consta da atestação paroquial e como por beneficio do mesmo menino para seus vestuários necessita dos salários que este Senado costuma pagar. (APM/ CMS-125, 1802, fl. 49)

Embora indicasse ter tratado da educação do menino, Joanna não usou os gastos com essa educação como argumento para obter da Câmara o pagamento dos valores em atraso pelos quase sete anos da criação de Manoel. Segundo alguns estudos, o cuidado para além da simples criação das crianças expostas pode muito bem indicar a possibilidade de relações de parentesco ou compadrio entre os criadores, as crianças e seus pais, o que justificaria o investimento em sua educação (Venâncio, 1999).

Há também petições de pessoas que haviam acolhido crianças expostas e que tentavam obter o auxílio tempos depois. Embora tais pedidos costumassem ser atendidos, o valor pago era, em geral, menor que as 12 oitavas anuais pagas aos criadores de expostos matriculados. Foi o caso de Jerônimo de Araújo da Cunha, que encaminhou petição dizendo estar criando um menino branco, enjeitado em sua porta. Por ser pobre, Jerônimo solicitou à Câmara o pagamento, o que lhe foi concedido, mas num valor muito inferior ao que corresponderia aos sete anos já passados. Em outros casos, a compreensão das disposições legais era distorcida, expressando a força das tradições assistencialistas presentes na cultura luso-brasileira do Antigo Regime, como aparece em petição de 1785 , feita por João Pereira do Lago, que dizia estar criando uma enjeitada de nome Simplícia, e que fazia isso com "muito amor e caridade". Afirmando saber que a Câmara "costuma dar esmolas" para alimentação e vestuário dos expostos, ele solicitava o pagamento, pois vivia “pobremente" (APM/CMS-75, 1785, fl. 119-120).

Muitas crianças continuavam aos cuidados dessas pessoas mesmo depois de terem completado os sete anos de idade, o que às vezes exigia que os criadores tratassem também de sua educação. Como esta era, em geral, direcionada para o aprendizado dos ofícios, os criadores tendiam a expandir as suas redes de relações, incluindo mestres e mestras de ofício, contratando-os e pagando-os. É preciso considerar que muitos desses criadores podiam ser os próprios pais das crianças, parentes ou conhecidos da família, já que não era incomum que lançassem mão da exposição de seus filhos - principalmente aqueles que padeciam de grande pobreza - a fim de receber o auxilio das Câmaras (Venâncio, 1999).

Era ainda estratégia corrente reconhecê-los em testamento, instituindo tutores que pudessem garantir seu sustento e educação, como fez Francisca Antonia de Miranda, solteira, ao declarar em seu testamento que "vencida pela fragilidade do meu sexo tive os filhos Luiz, Carlota e Carlos que estão em minha companhia e foram batizados e criados como expostos por honestidade". Ela instituía seu primo como tutor, considerando-o "abonado e capaz de velar e administrar as suas pessoas e legítimas quando dele espero e confio igualmente a educação e aumento deles" (APM/CMS-111, 1814).

A educação para o trabalho fazia-se por meio do envio das crianças para os mestres e mestras de oficio, com os quais aprenderiam a garantir o seu sustento, ajudando também a evitar que se desviassem do bom caminho. Na capitania de Minas Gerais, a maioria dos meninos criados com rendas das Câmaras era encaminhada para o aprendizado do oficio de alfaiate e da música. Esta última era particularmente procurada, pois a atividade musical era intensa, ativada pela freqüência das encomendas de composições e de execuções, pelas Câmaras e pelas irmandades e ordens terceiras. Muitos meninos e jovens atuavam como instrumentistas e como cantores nos coros e se apresentavam durante as festas civis e religiosas. Quanto ao oficio de alfaiate, parecia ter maior valor 
social, possivelmente por tratar-se de atividade artesanal mais sofisticada. Além disso, a intensidade da vida urbana nas Minas Gerais gerava maior demanda por vestuário, vinda não somente da população civil, mas também das milícias da capitania.

As meninas eram encaminhadas às mestras de costura, e era nesse ofício que se ocupavam as órfãs ou as que tinham sido expostas. $\mathrm{O}$ aprendizado da costura e dos bordados, além de ajudar no sustento, relacionava-se à educação moral das mulheres, já que ajudaria a evitar que elas tomassem o caminho da "desonestidade", como aconteceu à órfã Joana, filha de Catherina da Conceição, que fugiu da companhia da mulher com quem aprendia costura e bordado para viver na casa do cirurgião-mor Manoel da Costa Bacellar, fora do controle de seu tutor, "por se ter desonestado" (MO/ACBG/IPHAN. CPO-I (64) 475). A irmã de Joana, Josefa Francisca, ao contrário, encontrava-se, segundo o tutor, “com boa saúde, vivendo em companhia de sua irmã, ocupando-se no exercício de fiar, coser e tecer para si e vive com muita honestidade" (idem, grifo meu).

Nas Minas, foi somente no final do século XVIII que surgiram as primeiras iniciativas para a criação de instituições destinadas à educação dos pobres, como o Seminário do Vinculo do Jaguara, na Comarca do Rio das Velhas, cuja criação foi desejo do português Antonio de Abreu Guimarães. Ele viveu muitos anos em Minas Gerais como coronel dos auxiliares, e acumulou significativa fortuna, que resultou em várias fazendas na Comarca do Rio das Velhas - entre elas a de Jaguara -, todas "com engenhos, fábricas, casas, escravos, gados e criações, além de muitas léguas de terras minerais" (Alvará de 4 de junho de 1787...). De volta a Portugal, Guimarães solicitou à rainha $\mathrm{d}$. Maria I que parte de seus bens fosse vinculada, tornada inalienável e destinada a obras pias: dois hospitais e duas instituições educacionais na Comarca do Rio das Velhas, além de destinar uma parte para o Recolhimento das Convertidas do Rego de Lisboa. Em alvará de 1787, d. Maria I determinou o estabelecimento do Vínculo do Jaguara, juntamente com seu regimento. O alvará definia que, descontadas as partes cabíveis ao próprio instituidor e ao Recolhimento das Convertidas do Rego, deveriam ser fundados, em primeiro lugar, um seminário para a instrução de meninos pobres na Fazenda do Jaguara, e em seguida outro seminário para a educação de "donzelas necessitadas", um "hospital para a cura do mal de S. Lázaro" e outro para a cura de enfermidades não contagiosas. ${ }^{6}$

A instituição do vínculo, no entanto, só se deu em 1802, após a morte de Antonio de Abreu Guimarães (ocorrida em 1801, em Lisboa), ficando sob a administração de seu sobrinho, o coronel Francisco de Abreu Guimarães. Das obras pias que deveriam ser instituídas, só foram encontradas evidências documentais sobre o hospital para a cura de doenças não contagiosas e o seminário para meninos pobres. O hospital esteve sob a administração da Ordem Terceira de Nossa Senhora do Carmo até a criação, em 1832, da Santa Casa de Misericórdia de Sabará, que o incorporou. Quanto ao seminário, as fontes indicam que funcionou regularmente entre 1807 e 1811, atendendo alunos das localidades mais próximas da Vila de Sabará. O alvará determinava que se fizesse um regimento para o seminário, que "haja de servir de regra a quem o deva governar e aos Mestres e Seminaristas, assim pelo que pertence ao governo econômico, como também pelo que diz respeito à ordem e métodos dos estudos, e seus fins". 7 Também definia quem deveria compor a Junta de Administração do Vínculo e o reitor do Seminário dos Meninos.

O seminário oferecia o ensino das primeiras letras e da gramática latina, recebendo alunos com idades entre 6 e 20 anos, alguns deles porcionistas, além dos pobres, que não pagavam pelos estudos e que eram a maioria. O ingresso na instituição ocorria depois de uma avaliação da situação de cada postulante e, uma vez constatada sua pobreza e falta de condições para o pagamento dos estudos, o candidato era admitido e seu nome inscrito no livro de matrícula, na medida da existência de vagas. Esse processo era precedido

${ }^{6} \mathrm{O}$ regimento do alvará de 4 de junho de 1787 foi ligeiramente modificado pelo alvará de 5 de fevereiro de 1810 .

${ }^{7}$ Está no alvará de 4 de junho de 1787 . O regimento do seminário, se foi feito, ainda não foi localizado. 
do envio, pelo aluno ou por um representante, de um requerimento à Junta Administrativa, no qual manifestava o desejo de ingressar no seminário:

Dizem Manoel Pinto da Cunha e Raimundo Pinto da Cunha, filhos legítimos de José Pinto da Cunha e sua mulher Bárbara da Conceição, já falecida, naturais, batizados na Freguesia de Santo Antonio do Curvelo, e presentemente assistentes na mesma Freguesia, que eles suplicantes acham-se com idade suficiente para poderem aplicarem-se aos estudos das primeiras letras, mas não é possível poderem conseguir este tão grande beneficio pela nimia pobreza de seu Pai, que suposto ser de tão grande distancia, poderá haver quem conheça o miserável estado em que vivem, e porque tiveram a noticia de que esta Conspícua Junta ia quanto antes cumprir com as Pias fundações determinadas por Sua Majestade em beneficio da pobreza, segundo a mente do Instituidor deste Vinculo. Os suplicantes humildemente recorrem a Vossas Mercês para que se dignem admiti-los ao dito seminário das primeiras letras, para darem ultimo fim aos seus ardentes desejos, mandando proceder as suas matriculas. (BNRJ/ Coleção de Manuscritos, 18 dez. 1807)

Os candidatos pobres explicitavam as condições materiais que impediam o pagamento dos estudos, e o requerimento costumava vir acompanhado de outros documentos, como as atestações de pobreza, os certificados de batismo e os atestados de bons costumes, quase sempre passados pelos párocos das freguesias onde moravam.

Domingos Carvalho de Azevedo Presbitero secular, coadjutor atual nesta Freguesia de Nossa Senhora da Conceição do Sabará. Atesto e faço certo que José Simplício Guimarães filho legitimo do falecido Alferes Tomaz Rodrigues Guimarães, e Dona Maria Policarpa Casimira paroquianos desta mesma Freguesia é branco, de limpo sangue, órfão de pai, muito pobre, e de bons costumes, e por isso se faz digno, está na circunstância de ser admitido, e receber a graça de ser educado no seminário do Jaguara, que de novo se tem criado para instrução, educação da mocidade, e por verdade assino atestado. Sabará, 7 de dezembro de 1807. (BNRJ/ Coleção de Manuscritos, 7 dez. 1807)
Dos dezesseis requerimentos examinados, enviados à Junta Administrativa do Vínculo do Jaguara entre 1807 e 1809, somente um diz respeito a aluno porcionista, cujo pai requereu sua admissão no seminário mediante o pagamento da taxa estabelecida. ${ }^{8}$ Embora o número de requerimentos não seja elevado, sua diversidade sugere leituras que contrariam algumas afirmações mais tradicionais, de que os segmentos mais pobres da população atribuíam diminuto valor à educação escolar, que esses segmentos estariam quase sempre mergulhados na ilegitimidade ou que o ingresso de escravos e de seus filhos nas escolas estaria vedado por princípio. Além dos pobres, filhos legítimos e naturais, brancos ou não, o seminário recebeu também expostos e filhos de escravos. Nesses requerimentos, do total de 16 postulantes:

12 eram filhos legítimos, 1 filho natural, 2 expostos e 1 órfão;

2 foram declarados brancos e 2 pardos;

1 era filho de pai escravo e mãe forra;

12 foram imediatamente admitidos no seminário, 3 ficaram aguardando vaga e para 1 não consta registro.

Uma questão intrigante é por que alguns desses indivíduos procuraram o seminário, numa comarca onde havia inúmeras aulas régias, inclusive na região próxima à Fazenda do Jaguara, onde funcionou o seminário. Entre 1780 e 1814, havia mestres régios de primeiras letras e gramática latina nas Vilas de Sabará, Caeté e São Bento do Tamanduá, nos Arraiais de Curral del Rei e Sumidouro e na Freguesia de Santa Luzia, todas elas localidades próximas (APM/ CC-1290-041-E3). Hipóteses a serem consideradas é que a demanda pelos estudos fosse maior do que a capacidade de vagas das aulas régias, numa região de

${ }^{8} \mathrm{O}$ único registro localizado acerca de valores pagos pelos porcionistas refere-se ao montante que o vínculo do Jaguara deveria receber entre outubro de 1807 e agosto de 1810, e que seria de $289 \$ 422$, mas sem indicação sobre a quantos alunos corresponderia (BNRJ/Coleção de Manuscritos). 
considerável população, ${ }^{9}$ ou que o funcionamento das aulas régias existentes não era regular e não atendia, pois, às necessidades.

A criação de complexa estrutura administrativa, com expressivo número de funcionários civis e militares, em todas as vilas da capitania, abriu possibilidades para diferentes grupos. As habilidades da leitura e da escrita poderiam, para os segmentos menos favorecidos da população, possibilitar o ingresso nos níveis mais baixos da administração civil, a ocupação de algumas funções de destaque na organização das associações leigas ou mesmo a sobrevivência como escreventes particulares, prestando serviços à população. Esse quadro pode explicar intenções perceptíveis em alguns dos requerimentos de ingresso no Seminário do Jaguara, nos quais parecia premente a necessidade da instrução:

Diz Joaquim José de Araújo, filho legitimo de Francisco José de Araújo Guimarães e de Catharina Ferreira Leite, já falecida, natural e morador desta mesma Freguesia de Santa Luzia, de idade de treze anos, que seu Pai se acha na maior decadência de bens e pobreza, [pencionado] com muitos filhos, de tal sorte que até agora não tem podido mandar instruir o suplicante nas primeiras letras nem ao menos assistir-lhe com o perciso vestuário, como a Vossas Mercês é bem constante, e porque o suplicante não tem outros meios alguns de procurar a sobredita instrução como tanto deseja, recorre a Piedade de Vossas Mercês para que se dignem usar com ele da graça concedida por Sua Majestade em beneficio da pobreza, admitindo-o ao seminário para ser instruído ao menos nas primeiras letras, de que muito necessita, e mandando para isso matriculá-lo no livro competente. (BNRJ/ Coleção de Manuscritos, 18 dez. 1807, grifo meu)

Diz Miguel pardo de idade de 8 anos filho legitimo de Luiz da Cruz escravo, e de Antonia Coelha parda forra, nascido e batizado nesta mesma Freguesia, que ele suplicante se acha na precisão de ser instruído nas primeiras letras, o que não pode conseguir pela sua muito grande e conhecida pobreza, e por agora vai o suplicante valer-se da inata Piedade de Vossas Mercês para que atendendo a sua indigência se

${ }^{9}$ Estima-se que em 1808 a Vila de Sabará teria, no conjunto, cerca de 76.000 habitantes. dignem piedosamente admiti-lo a este seminário do Jaguara, aonde se instrui nas sobreditas aos meninos pobres. (BNRJ/

Coleção de Manuscritos, 25 dez. 1809)

Mesmo que não fossem em grande número, escravos, forros e seus filhos podiam ter acesso à instrução das primeiras letras. Em alguns casos, os próprios senhores mandavam instruí-los, a fim de obter mais proveito com o aluguel de escravos qualificados (Paiva, 2003). Para estes, ou para seus filhos, o letramento poderia servir também como instrumento para a obtenção de vantagens, inclusive a liberdade. Os objetivos primordiais do estabelecimento de fundações pias como o seminário para meninos pobres do Vínculo do Jaguara eram, assim, ultrapassados, numa região onde as ações e intenções dos poderes constituídos nem sempre se efetivavam. O interesse suscitado pelo Seminário do Jaguara aponta, assim, para a existência das necessidades sociais e culturais na aquisição do letramento.

A maior parte dos documentos localizados sobre o seminário refere-se ao período em que se tentou a reestruturação do vínculo, logo após a morte do sobrinho do instituidor. Durante sua gestão como presidente da Junta Administrativa, não houve prestação de contas nem funcionamento eficaz das fundações pias. A junta iniciou um movimento pela recomposição das rendas e do funcionamento das fazendas e das fundações, reorganizou o quanto pôde as contas a partir de 1805 e reabriu o Seminário de Educação de Meninos em 1807. Isso explica a maior concentração dos documentos relativos a esse período, embora ainda não se tenha notícia dos livros de matriculas e dos estatutos da instituição.

Entre 1807 e 1811, o seminário funcionou regularmente, não obstante as dificuldades financeiras do Vínculo do Jaguara, que lutava para manter as rendas da produção de suas fazendas e sentia o peso da queda da produção do ouro. Além dos gastos com o pagamento dos mestres de gramática latina e de primeiras letras, havia também as compras de material (papel, tinteiros), calçados e tecidos para a confecção de roupas para os alunos, além de remédios e gêneros que as fazendas porventura não produzissem (BNRJ/Coleção de Manuscritos, 1810; 1807; 07/09/1814). A partir de 1814, a má administração, a queda na produção e as dívidas 
acumuladas tornaram mais difícil a manutenção tanto do seminário quanto do hospital. Daí em diante, embora o vínculo continuasse a existir até a segunda metade do século XIX, desaparecem as referências ao seminário para meninos pobres. O hospital passou à Santa Casa de Misericórdia em 1832, e a Fazenda do Jaguara sobreviveu independentemente do vínculo, até os dias atuais, passando por vários proprietários. Ao que tudo indica, a assistência aos pobres fora do âmbito das irmandades e ordens terceiras, principalmente na Vila de Sabará e seu Termo, ficou a cargo da Santa Casa de Misericórdia, que viu misturarem-se entre suas funções o atendimento aos doentes não contagiosos e a educação, tornando ainda mais difíceis as suas condições. Conforme destacava em 1828 o procurador da Ordem Terceira de Nossa Senhora do Carmo, ainda responsável pelo hospital, além dos doentes ainda lá havia

[...] 16 educandos a aprenderem a ler, escrever, cozer etc. Como é isto compatível em um Hospital, onde deve reinar o silêncio, e o mais perfeito sossego, para a tranqüilidade, e alivio dos desgraçados enfermos? Por ventura seria a mente do Instituidor, e dos Soberanos Decretos, que a autorizou, que uma casa destinada para a cura dos enfermos houvesse de transformar em casa de educação? Por certo que ninguém avançará um tão absurdo paradoxo. (Representação, apud Passos, 1929, p. 90)

Instrução e assistência fizeram par no mundo lusobrasileiro do Antigo Regime, mas se interligaram de forma peculiar na capitania de Minas Gerais. Embora seguindo os ditames da legislação e comungando dos mesmos valores básicos em relação ao atendimento aos pobres, principalmente as crianças e os jovens, nesta parte da América portuguesa sua efetiva ação esteve nas mãos das Câmaras e dos leigos, não raro mais preocupados com a assistência do que com a educação. Iniciativas como o Seminário do Vínculo do Jaguara tiveram existência efêmera, e no século XIX, ao lado das escolas públicas já no período do Brasil independente, floresceram os educandários confessionais para meninos e para meninas, mas que pouco tinham de assistencialistas, tornando-se centros para a educação das elites mineiras, no Império e na República.

\section{Fontes primárias}

ALVARÁ de 4 de junho de 1787 com o Regimento de 23 de Novembro de 1787 para a administração dos bens legados por Antônio de Abreu Guimarães para Estabelecimentos de piedade na Comarca do Sabará. Disponível em: <http://www.iuslusitaniae.fcsh.unl.pt>. Acesso em: 4 out. 2008.

ARQUIVO PÚBLICO MINEIRO (Belo Horizonte)/IPHAN. CMS75, Prestação de contas, despesas gerais, execução de ouvidoria, 1785, fl. 119-120.

.CMS-111. Livro de Registro de Testamentos (1800-

1845). Testamento de Francisca Antonia de Miranda, 1814. CC-1290-041-E3. Folha do Subsidio Literário. Capitania de Minas Gerais.

BIBLIOTECA NACIONAL DO RIO DE JANEIRO/Coleção de Manuscritos. Requerimento ao presidente e aos deputados solicitando que sejam admitidos no seminário de primeiras letras. Jaguara, 18 dez. 1807

Atestado comprovando a boa formação e os bons costumes de José Simplício Guimarães, o que possibilita sua admissão no Seminário do Jaguara. Sabará, 7 dez. 1807.

O Vínculo do Jaguara em sua conta corrente desde 11 de outubro de 1807 até 31 de agosto de 1810; Requerimento solicitando que seja admitido no seminário para que possa receber aulas de primeiras letras. Jaguara, 18 dez. 1807

. Requerimento solicitando que, por sua pobreza, seja admitido com aulas de primeiras letras em Jaguara. Jaguara, 25 fev. 1809

Extrato de contas dos anos de 1808 a 1810 apresentados a Junta administrativa do Vinculo do Jaguara por Joaquim Gonçalves da Silva e Costa, Procurador Geral do mesmo e José Carlos Caetano Monteiro Guedes, secretário; Cópia autentica da conferencia de 18/12/1807 que se acha lançada no respectivo livro das conferencias. Fazenda do Jaguara, 1807.

Oficio dos administradores do Vinculo do Jaguara a V.A.R. para que Sua Majestade faça recair sobre a administração do Vinculo suas pias deliberações. Junta do Vinculo do Jaguara, 7 set. 1814.

MUSEU DO OURO/ ARQUIVO CASA BORBA GATO (SABARÁ, MINAS GERAIS)/IPHAN. CSO-I (19) 163. Inventário dos bens que ficaram da falecida Antonia Rangel de Abreu, 1757. . CPO-I (64) 475. Inventário de Catherina da Conceição, 1788.

REPRESENTAÇÃO do Procurador da Ordem Terceira de Nossa Senhora do Carmo à Mesa. 9 de abril de 1828, apud PASSOS, Z. 
V. Notícia histórica da Santa Casa de Sabará (1787-1928). Belo Horizonte, 1929. p. 90.

REVISTA DO ARQUIVO PÚBLICO MINEIRO. Ordem de 16 de abril de 1738. Coleção sumária das primeiras leis, cartas régias, avisos e ordens que se acham nos livros da Secretaria do Governo desta Capitania de Minas Gerais, deduzidas por ordem a títulos separados. Título $7^{\circ}$ - Religiões, clérigos e matérias eclesiásticas. Belo Horizonte: Imprensa Oficial, v. 16, 1911.

Informações sobre o Recolhimento do Arraial da Chapada, Termo de Minas Novas (1780). Belo Horizonte: Imprensa Oficial, v. 2, 1897. p. 350-354.

\section{Referências bibliográficas}

ADÃO, Áurea. Estado absoluto e ensino das primeiras letras: as escolas régias (1772-1794). Lisboa: Fundação Calouste Gulbenkian, 1997.

ALGRANTI, Leila Mezan. Honradas e devotas: mulheres na colônia. Condição feminina nos conventos e recolhimentos do sudeste do Brasil (1750-1822). Rio de Janeiro: José Olympio; Brasília: Edunb, 1993.

ALMEIDA, Cândido Mendes de (Org.). Ordenações filipinas, primeiro livro. Título LXXXVIII. Rio de Janeiro: s.ed., 1870.

BARBOSA, Waldemar de Almeida. Dicionário histórico e geográfico de Minas Gerais. Belo Horizonte: Itatiaia, 1985.

BOSCHI, Caio César. Os leigos e o poder: irmandades leigas e política colonizadora em Minas Gerais. São Paulo: Ática, 1986.

CAMPOS, Adalgisa Arantes. A terceira devoção do setecentos mineiros: o culto a São Miguel e Almas. Tese (Doutorado em História) - Faculdade de Filosofia, Letras e Ciências Humanas, Universidade de São Paulo, São Paulo, 1994.

Cultura barroca e manifestações do rococó nas

Gerais. Ouro Preto: FAOP/BID, 1998.

CARRATO, José Ferreira. Igreja, iluminismo e escolas mineiras coloniais. São Paulo: Companhia Editora Nacional, 1968.

COELHO, José João Teixeira. Instrução para o governo da Capitania de Minas Gerais. Belo Horizonte: Fundação João PinheiroCentro de Estudos Históricos e Culturais, 1994.

FONSECA, Thais Nivia de Lima E. Segundo a qualidade de suas pessoas e fazenda: estratégias educativas na sociedade mineira colonial. Vária história, Belo Horizonte: Departamento de História, Programa de Pós-Graduação em História, Faculdade de Filosofia e
Ciências Humanas, Universidade Federal de Minas Gerais, v. 22, n. 35, jan./jun. 2006.

FURTADO, Júnia Ferreira. Chica da Silva e o contratador dos diamantes: o outro lado do mito. São Paulo: Companhia das Letras, 2003.

MATOS, Raimundo José da Cunha. Corografia histórica da Província de Minas Gerais. Belo Horizonte: Imprensa Oficial, 1981. PAIVA, Eduardo França. Leituras (im)possíveis: negros e mestiços leitores na América portuguesa. Colóquio Internacional: política, nação e edição, Belo Horizonte: Programa de Pós-Graduação em História, Universidade Federal de Minas Gerais, 2003. (Mimeografado.)

PASSOS, Zoroastro Vianna. Notícia histórica da Santa Casa de Sabará (1787-1928). Belo Horizonte: Imprensa Official de Minas Gerais, 1929.

VALADARES, Virgínia Trindade. Elites mineiras setecentistas: conjugação de dois mundos. Lisboa: Colibri, 2004.

VASCONCELOS, Diogo Pereira Ribeiro de. Breve descrição geográfica, física e política da Capitania de Minas Gerais. Belo Horizonte: Fundação João Pinheiro, 1995.

VENÂNCIO, Renato Pinto. Famílias abandonadas. Assistência à criança de camadas populares no Rio de Janeiro e em Salvador séculos XVIII e XIX. Campinas: Papirus, 1999.

THAIS NIVIA DE LIMA E FONSECA, doutora em história social pela Universidade de São Paulo (USP) e com pós-doutorado em história pela Universidade Federal Fluminense (UFF) e pela Universidade de Lisboa, é professora da Faculdade de Educação e do Programa de Pós-Graduação em Educação da Universidade Federal de Minas Gerais (UFMG), na qual coordena o Grupo de Estudos e Pesquisas em História da Educação (GEPHE). Publicações recentes: organizou ainda com Cynthia Greive Veiga, História e historiografia da educação no Brasil (Belo Horizonte: Autêntica, 2003); Inaugurando a história e construindo a nação: discursos e imagens no ensino de história (Belo Horizonte: Autêntica, 2001); História \& ensino de história (Belo Horizonte: Autêntica, 2003). Pesquisa atual: "Sociabilidades e práticas educativas na capitania de Minas Gerais (1730-1822)", financiada pela Fundação de Amparo à Pesquisa do Estado de Minas Gerais (FAPEMIG).E-mail: thais.fonseca@pq.cnpq.br

Recebido em outubro de 2007 Aprovado em junho de 2008 
objective of this dissertation which analysed diverse documents on public education is to demonstrate the popular character of the school in the Empire and argument that its failure in the function of educating and civilizing poor, negro and mixed-race children is exactly in the characterization of the clientele at whom the public school was aimed in the XIX century as non-educable. The importance of the theme for deepening the debate on the history of the school in Brazil is also highlighted.

Key words: history of education; imperial education; public school; social class; race

Escuela pública para los negros y los pobres en Brasil: un invento imperial El artículo presenta datos finales de estudios sobre la escolarización de niños pobres, negros y mestizos en Brasil, específicamente en la provincia de Minas Gerais durante la vigencia de la Monarquía constitucional (18241889). Para su desarrollo fueron investigados diferentes documentos de la instrucción pública y la principal tesis es demostrar el carácter popular de la escuela del Imperio y discutir sobre como su fracaso en la función de instruir y civilizar pobres, negros y mestizos puede estar exactamente relacionada con la descalificación de la condición de educabilidad de la clientela a la cual se destinaba la escuela pública del siglo XIX. Destaca también la importancia de la temática para la ampliación de los debates sobre la historia de la escuela en Brasil.

Palabras clave: historia de la educación; educación imperial; escuela pública; clase social; etnia

Petrônio Domingues

\section{Um “templo de luz": Frente Negra Brasileira (1931-1937) e a questão da educação \\ $\mathrm{O}$ artigo examina como a Frente Negra}

Brasileira (1931-1937) - considerada a maior e mais importante organização negra que se projetou no cenário nacional após a abolição da escravatura - discutiu, problematizou e tratou a questão da educação. Verifica-se como as lideranças dessa organização tinham uma visão crítica em relação à falta de políticas públicas voltadas à população negra e concebiam a educação como uma ferramenta estratégica para a inserção desse segmento populacional à sociedade. Além da integração social, a educação possibilitaria a eliminação dos preconceitos e, em última instância, garantiria as condições para o exercício da cidadania plena.

Palavras-chave: negros; relações raciais; educação; multiculturalismo

\section{A "temple of light": the Brazilian} Negro Front (Frente Negra Brasileira) (1931-1937) and the education question

The article analyses how the Brazilian Negro Front (1931-1937) - considered the largest and most important black organization to be projected on the national scene after the abolition of slavery-discussed, questioned and dealt with the issue of education. It can be observed that the leaders of that organization had a critical vision of the lack of public policies for the black population and saw education as a strategic tool for the social integration of this segment of the population. In addition to social integration, education would make possible the elimination of prejudice and, ultimately, would ensure the conditions for the exercise of full citizenship.

Key words: negroes; race relations; education; multiculturalism

\section{Un “templo de luz": Frente Negra Brasileña (1931- 1937) y la cuestión de la educación \\ El artículo examina como la Frente Negra Brasileña (1931-1937) - considerada la mayor y la más}

importante organización negra que se ha proyectado en el escenario nacional después de la abolición de la esclavitud - discutió, problematizó y trató la cuestión de la educación. Se comprueba como las lideranzas de esa organización tenían una visión crítica en relación a la falta de políticas públicas destinadas a la populación negra y concebían la educación como una herramienta estratégica para la inserción de ese segmento popular a la sociedad. Además de la integración social, la educación posibilitaría la eliminación de los perjuicios y, en última instancia, garantiría las condiciones para el ejercicio da la plena ciudadanía.

Palabras clave: negros; relaciones raciales, educación; multiculturalismo

Thais Nivia de Lima e Fonseca

Instrução e assistência na capitania de Minas Gerais: das ações das câmaras às escolas para meninos pobres (1750-1814)

Neste artigo, pretende-se discutir as relações entre a função civilizadora da instrução e de seu papel assistencial pelo estudo das ações das câmaras e de instituições pias para a educação de meninos pobres. No Antigo Regime, a educação para as camadas mais baixas da população associava-se à difusão da doutrina cristã e à formação profissional como meios de controle e era realizada em instituições assistencialistas. O ensino das primeiras letras visava facilitar o aprendizado da doutrina, sem criar possibilidades de ascensão social pela educação. Sobressaía a solução da educação profissional, do aprendizado de ofícios que pudessem servir de ocupação e de sustento. A legislação portuguesa definia os destinos a serem dados aos órfãos, e a educação que lhes seria destinada deveria ser compatível com seu nível social de origem. Na América 
portuguesa, especialmente na capitania de Minas Gerais, a presença das ordens religiosas foi proibida no início do século XVIII, e a assistência associada à instrução limitou-se à sua dimensão leiga ou esteve a cargo do Estado. Somente no final dos Setecentos é que surgiram instituições para a instrução dos pobres. Palavras-chave: Minas Gerais; história da educação; instrução elementar; assistência; escola

\section{Instruction and assistance in the} captaincy of Minas Gerais: from the actions of the chambers to schools for poor children (1750-1814) In this article we discuss the relations between the civilizing function of instruction and its charitable role based on a study of the actions of the chambers and religious institutions in favour of education for poor children. In the Ancient Regime, education for the lowest strata of the population was associated with the diffusion of the Christian doctrine and vocational training as a means of control carried out by charitable institutions. The teaching of the first letters was aimed at facilitating the learning of doctrine without creating the possibility of social ascension by means of education. The solution of vocational education, the learning of trades which could serve as an occupation and sustenance, was emphasized. The Portuguese legislation defined the destination to be given to orphans and the education which was destined to them had to be compatible with their original social status. In Portuguese America, especially in the captaincy of Minas Gerais, the presence of religious orders was prohibited at the beginning of the $18^{\text {th }}$ century and the assistance associated with instruction was limited to its lay dimension or was the responsibility of the State. Only at the end of the century did institutions for the instruction of the poor arise. Key words: Minas Gerais; history of education; elementary instruction, assistance; school

Instrucción y asistencia en la capitania de Minas Gerais: de las acciones de las cámaras a las escuelas para niños pobres (1750-1814)

En este artículo, se pretende discutir las relaciones entre la función civilizadora de la instrucción y de su papel de asistencia por el estudio de las acciones de las cámaras y de instituciones propias para la educación de niños pobres. En el Antiguo Régimen, la educación para las clases más bajas de la población se asociaba a la difusión de la doctrina cristiana y a la formación profesional como medios de control y, era realizada en instituciones de asistencia. La enseñanza de las primeras letras visaba facilitar el aprendizaje de la doctrina, sin crear posibilidades de ascensión social por la educación. Sobresalía la solución de la educación profesional, del aprendizaje de oficios que pudieran servir de ocupación y de sustento. La legislación portuguesa definía los destinos que serían dados a los huérfanos y, la educación que les sería destinada devería ser compatible con su nivel social de origen. En la América portuguesa, especialmente en la capitanía de Minas Gerais, la presencia de las órdenes religiosas fue prohibida en el inicio del siglo XVIII y, la asistencia asociada a la instrucción se limitó a su dimensión lega o estuvo a cargo del Estado. Solamente al final de los Setecientos es que surgieron instituciones para la instrucción de los pobres.

Palabras clave: Minas Gerais; historia de la educación; instrucción elemental; asistencia; escuela

Juares da Silva Thiesen

A interdisciplinaridade como um movimento articulador no processo ensino-aprendizagem

Discute a interdisciplinaridade como um movimento contemporâneo presente nas dimensões da epistemologia e da pedagogia, que vem marcando o rompimento com uma visão cartesiana e mecanicista de mundo e de educação e, ao mesmo tempo, assumindo uma concepção mais integradora, dialética e totalizadora na construção do conhecimento e da prática pedagógica. Inicialmente, faz-se uma breve apresentação da origem histórica desse movimento, discutem-se aspectos de sua conceituação e suas implicações no campo das diferentes ciências contemporâneas para então apresentar a interdisciplinaridade como um importante fenômeno de articulação do processo de ensino e aprendizagem. A argumentação apresentada no texto busca destacar que o movimento da interdisciplinaridade pode transformar profundamente a qualidade da educação escolar por intermédio de seus processos de ensino.

Palavras-chave: interdisciplinaridade; ciência; educação; processo de ensino e aprendizagem; conhecimento

\section{Interdisciplinarity as an articulating movement in the teaching-learning process}

The text discusses interdisciplinarity as a contemporary movement, present in epistemological and pedagogical dimensions. This movement is marking a break with the Cartesian and mechanist vision of the world and education and, at the same time, assuming a more integrated, dialectic and totalizing conception in the construction of knowledge and in pedagogic practice. To begin with, I make a brief presentation of the historical origin of the movement and discuss aspects of its conceptualization and its implications in the field of different contemporary sciences before presenting interdisciplinarity as an important phenomenon of the articulation of the teaching-learning process. The argument presented in the text seeks to 